Article

\title{
A Highly Stretchable, Tough, Fast Self-Healing Hydrogel Based on Peptide-Metal Ion Coordination
}

\author{
Liang Zeng ${ }^{1,+}$, Mingming Song ${ }^{2,+}$, Jie Gu ${ }^{2}$, Zhengyu $\mathrm{Xu}^{2}$, Bin Xue ${ }^{2, *}$, Ying $\mathrm{Li}^{1, *}$ (1) and \\ Yi Cao ${ }^{2, * \mathbb{D}}$ \\ 1 Collaborative Innovation Center of Atmospheric Environment and Equipment Technology, \\ Jiangsu Key Laboratory of Atmospheric Environment Monitoring and Pollution Control, \\ School of Environmental Science and Engineering, Nanjing University of Information Science \& Technology, \\ Nanjing 210044, China; 20161244375@nuist.edu.cn \\ 2 Collaborative Innovation Center of Advanced Microstructures, National Laboratory of Solid State \\ Microstructure, Key Laboratory of Intelligent Optical Sensing and Manipulation, Ministry of Education, \\ Department of Physics, Nanjing University, Nanjing 210093, China; 151120102@smail.nju.edu.cn (M.S.); \\ 131242017@smail.nju.edu.cn (J.G.); 151242051@smail.nju.edu.cn (Z.X.) \\ * Correspondence: xuebinnju@nju.edu.cn (B.X.); yingli@nuist.edu.cn (Y.L.); caoyi@nju.edu.cn (Y.C.) \\ + These authors contributed equally to this work.
}

Received: 14 February 2019; Accepted: 6 May 2019; Published: 10 May 2019

\begin{abstract}
Metal coordination bonds are widely used as the dynamic cross-linkers to construct self-healing hydrogels. However, it remains challenging to independently improve the toughness of metal coordinated hydrogels without affecting the stretchability and self-healing properties, as all these features are directly correlated with the dynamic properties of the same metal coordination bonds. In this work, using histidine- $\mathrm{Zn}^{2+}$ binding as an example, we show that the coordination number (the number of binding sites in each cross-linking ligand) is an important parameter for the mechanical strength of the hydrogels. By increasing the coordination number of the binding site, the mechanical strength of the hydrogels can be greatly improved without sacrificing the stretchability and self-healing properties. By adjusting the peptide and $\mathrm{Zn}^{2+}$ concentrations, the hydrogels can achieve a set of demanding mechanical features, including the Young's modulus of 7-123 kPa, fracture strain of $434-781 \%$, toughness of $630-1350 \mathrm{~kJ} \mathrm{~m}^{-3}$, and self-healing time of $\sim 1 \mathrm{~h}$. We anticipate the engineered hydrogels can find broad applications in a variety of biomedical fields. Moreover, the concept of improving the mechanical strength of metal coordinated hydrogels by tuning the coordination number may inspire the design of other dynamically cross-linked hydrogels with further improved mechanical performance.
\end{abstract}

Keywords: self-healing; hydrogel; stretch-ability; metal ion coordination

\section{Introduction}

Self-healing hydrogels have received considerable attention in recent years due to their diverse biomedical applications, such as wound dressing, soft tissue medical adhesives, injectable drug carriers, and self-supporting 3D printing inks [1-8]. Generally, self-healing hydrogels can use either dynamic covalent or noncovalent cross-linkers as the healing motifs. Dynamic covalent cross-linkers include boronate ester bonds [9-14], imine bonds [15,16], acylhydrazone bonds [17,18], and oxime bonds [19], etc. These bonds are chemically labile under physiological conditions. Despite that the hydrogels cross-linked by dynamic covalent cross-linkers possess high mechanical stability, they self-heal slowly, as typical dynamic covalent bonds show very slow exchange dynamics. On the other hand, physical cross-linkers, including hydrophobic effects [20-23], hydrogen bonding [24-29], host-guest 
interactions [30-32], ionic bonding [33], metal coordination [34-46], and specific protein-protein interactions [47-49], are highly dynamic, rendering the hydrogels with great self-healing properties. However, they are typically too dynamic to give rise to mechanically tough hydrogels, because mechanical strength of hydrogels is also directly correlated with the cross-linker dynamics [34,50-52]. Therefore, in most self-healing materials, the toughness and the healing rates are compromised. It remains challenging to engineer mechanically tough yet highly stretchable and fast healable hydrogels.

Recently Holten-Andersen et al. experimentally [53], and Hartmann et al. theoretically [54], showed that the coordination number, which is the number of ligands involved in the cross-linking junction, is critical for the mechanical properties of the resulting hydrogels. By increasing the number of cross-linking sites using $\mathrm{Fe}_{3} \mathrm{O}_{4}$ nanoparticles instead of $\mathrm{Fe}^{3+}$ ions with catechol, the hydrogels became much tougher yet remained reversible [53]. Increasing the coordination number has a beneficial effect on the mechanical strength of the hydrogels due to the cooperative rupture of these bonds upon loading [54].

Inspired by these studies, here we report on the construction of highly stretchable, tough and fast self-healing hydrogels cross-linked by peptide-metal ion coordination sites with high coordination number (the number of binding site in each cross-linking ligand). We show that comparing to the hydrogels cross-linked by single ligand-metal ion bonds, the peptide-metal ion coordinated hydrogels show much higher Young's modulus and break strength as well as similar break strain and self-healing rate. We anticipate that these hydrogels can find broad biomedical applications in tissue engineering, wound addressing and 3D bioprinting.

\section{Materials and Methods}

\subsection{Materials}

Acrylamide was purchased from Sigma-Aldrich (Shanghai, China). Zinc chloride $\left(\mathrm{ZnCl}_{2}\right)$, potassium chloride $(\mathrm{KCl})$, ammonium persulfate (APS), hydrochloric acid $(\mathrm{HCl})$, and tris(hydroxymethyl)methyl aminomethane (Tris base) were purchased from Sinopharm Chemical Regent Co., Ltd. (Beijing, China). The designed peptides were purchased from GL Biochem (Shanghai) Ltd. (Shanghai, China). All regents were used without further purification.

\subsection{Preparation of the Gly-Gly-His (GGH) and Gly-His-His-Pro-His (GHHPH) Hydrogels}

In a typical preparation of hydrogels, peptides and acrylamide were dissolved in Milli-Q water to the concentrations of $100 \mathrm{mg} \mathrm{mL}^{-1}$ and $50 \mathrm{mg} \mathrm{mL}^{-1}$, respectively. The solution was degassed three times for $15 \mathrm{~min}$ by ultrasound under argon atmosphere. Ammonium persulfate was added as a photoinitiator for polymerization. The solutions were filled into the molds and polymerization was undertaken under ultraviolet light $(285 \mathrm{~nm})$ irradiation for $20 \mathrm{~h}$. Then the hydrogels were immersed in $1 \mathrm{M}$ Tris buffer ( $\mathrm{pH}=7.60$, containing $300 \mathrm{mM}$ of $\mathrm{KCl}$ and different molars of $\mathrm{ZnCl}_{2}$ ) for $24 \mathrm{~h}$ to form the coordinate bonds. The solid content $\left(W_{s}\right)$ of the hydrogels was calculated as $W_{s}=\frac{W_{d}}{W_{0}}$, where $W_{\mathrm{d}}$ is the weight of the lyophilized hydrogel and $W_{0}$ corresponds to the weight of the corresponding wet hydrogel. The molecular weights of the polymers were characterized using gel permeation chromatography (GPC) (LC-20A, Shimadzu, Japan) in THF with tandem Shodex KF-803 and KF-805 columns. The molecular weights were calibrated using the polystyrene molecular weight standard (ZZStandard, Shanghai, China). Then the degree of polymerization was calculated based on the molecular weights of the polymers and the molar ratio of peptides and acrylamide in the hydrogels.

\subsection{Rheological Measurements}

The rheological measurements were carried out on a standard rheometer (Thermo Scientific Haake RheoStress 6000, Thermo, Karlsruhe, Germany). The hydrogels were carefully placed on the rheometer plate and allowed to equilibrate for $\sim 30 \mathrm{~min}$ prior to the measurements. The rheology experiments were then carried out either using a strain sweep mode with a strain amplitude range of $0.01 \%$ to 
$100 \%$ at a fixed frequency of $6.28 \mathrm{rad} \mathrm{s}^{-1}$ or using a frequency sweep mode with a frequency range of $0.01 \mathrm{rad} \mathrm{s}^{-1}$ to $100 \mathrm{rad} \mathrm{s}^{-1}$ at a fixed strain of $0.1 \%$ (geometry: $1^{\circ} / 20 \mathrm{~mm}$ of cone and plate; gap: $0.37 \mathrm{~mm}$; temperature: $20^{\circ} \mathrm{C}$ ). For the recovery experiments, the $\mathrm{G}^{\prime}$ and $\mathrm{G}^{\prime \prime}$ were measured at a strain of $0.1 \%$ and a frequency of $6.28 \mathrm{rad} \mathrm{s}^{-1}$. Then strain was set to an amplitude of $1000 \%$ to destroy the hydrogels for $60 \mathrm{~s}$ and switched back to an amplitude of $0.1 \%$ to monitor the recovery of the mechanical properties for $300 \mathrm{~s}$.

\subsection{Tensile and Compressive Test}

The tensile stress-strain measurements were performed on a tensile-compressive tester (Instron-5944 with a $10 \mathrm{~N}$ sensor, Instron, Boston, MA, USA) in air at room temperature. In the tension crack test, the strain rate of stretching was maintained at different percentages of the original length of the samples per minute and the original length of the hydrogel samples in the uniaxial tension ranged from $7.5 \mathrm{~mm}$ to $10.0 \mathrm{~mm}$. The tensile toughness was calculated from the area below the stress-strain curve until fracture. The equation used in the calculation was as below; $E_{\mathrm{f}}=\int_{x_{0}}^{x_{\mathrm{f}}} \sigma(x) d x$ in which $x_{0}$ corresponds to the starting point of the tension, corresponds to the fracture point of the tension and $\sigma$ corresponds to the stress during the tension. [55-57] The Young's moduli, E, were measured by fitting the linear region of the stress-strain curve (below 20\% strain). The definitions of all the parameters and formulations are listed in Table S1.

\subsection{Scanning Electron Microscopy (SEM) measurements}

SEM images were obtained using a Quanta Scanning Electron Microscope (Quata 200, FEI, Thermo, Hillsboro, OR, USA) at $20 \mathrm{kV}$. The hydrogels were lyophilized prior to the measurement.

\section{Results}

\subsection{Results and Analysis}

\subsubsection{The Design and Preparation of the Self-Healing Hydrogels}

Two kinds of short peptides containing different number of metal ion binding sites (histidine) [58,59] were used as the cross-linkers in the self-healing hydrogels. The sequences of the two peptides are Gly-Gly-His (GGH) and Gly-His-His-Pro-His (GHHPH), respectively (Figure 1A,B). The histidine residues in both peptides can form coordination bonds with $\mathrm{Zn}^{2+}$ ions. The GGH peptide contains only a single histidine and forms a single coordination bond with $\mathrm{Zn}^{2+}$ ions. In contrast, GHHPH can bind with $\mathrm{Zn}^{2+}$ ions with a 2:1 stoichiometric ratio as previously reported [60], indicating that GHHPH forms at least two coordination bonds with $\mathrm{Zn}^{2+}$, exhibiting higher coordination number (the number of binding site in each cross-linking ligand) than GGH. Although metal coordination bonds can be directly conjugated to multiarmed hydrophilic polymers to form metal chelating hydrogels, the mechanical properties of those networks were relatively weak due to the limited cross-linking density [34,44]. We therefore used an aqueous free radical copolymerization approach to polymerize the hydrophilic monomer (acrylamide) and the acryloyl-terminated peptides directly into an entangled weak network of pre-gels (Figure 1C). The pre-gels were in the boundary of hydrogels and viscous solutions whose storage moduli were close to the loss moduli in a broad frequency range (Figure S1). There was no inter-chain covalent cross-linking in the pre-gels. Then, the pre-gels were immersed in Tris buffer $(\mathrm{pH}=7.60,100 \mathrm{mM}$ Tris and $300 \mathrm{mM} \mathrm{KCl})$ containing different concentrations of $\mathrm{ZnCl}_{2}$ for $48 \mathrm{~h}$ in order to form coordination bonds between peptides and $\mathrm{Zn}^{2+}$ ions (Figure 1C). The hydrogels (denoted as GGH and GHHPH hydrogels) were transparent and free-standing (Figure 1D). The microstructures of the hydrogels were studied by scanning electron microscopy (SEM). Both the two kinds of hydrogels exhibited similar microstructures of porous networks (Figure S2). 
A<smiles>NCC(=O)NCC(=O)NC(Cc1c[nH]cn1)C(=O)O</smiles>

B<smiles>NCC(=O)NC(Cc1cnc[nH]1)C(=O)NC(Cc1cnc[nH]1)C(=O)N1CCCC1C(=O)NC(Cc1c[nH]cn1)C(=O)O</smiles>

C
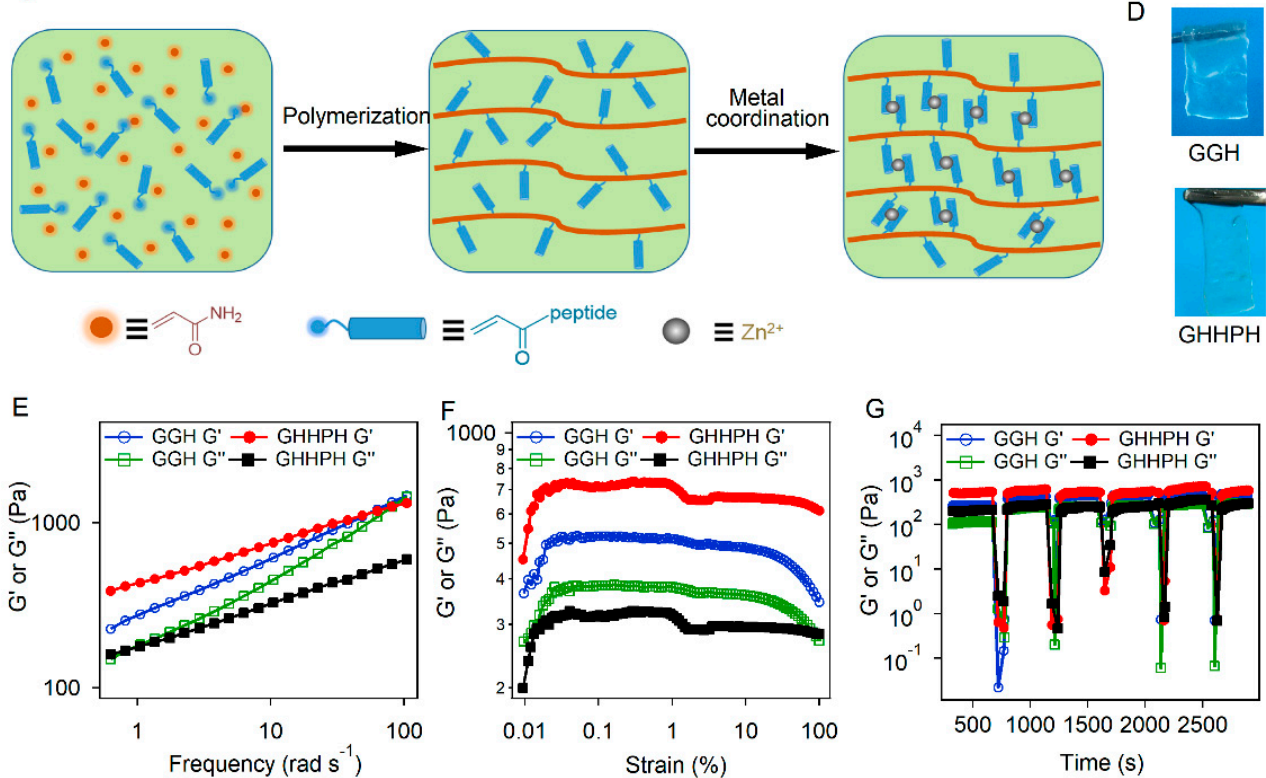

Figure 1. Illustrative scheme and rheological mechanical properties of the self-healing hydrogels based on the coordination interactions between peptides and $\mathrm{Zn}^{2+}$ ions. (A) Chemical structure of the GGH peptide. (B) Chemical structure of the GHHPH peptide. (C) Schematic illustration of the hydrogels based on the coordination interactions between the designed peptides and $\mathrm{Zn}^{2+}$ ions. (D) Images corresponding to GGH and GHHPH hydrogels. (E) $G^{\prime}$ and $G^{\prime \prime}$ of the hydrogels measured in a frequency sweep experiment (frequencies from 0.01 to $100 \mathrm{rad} \mathrm{s}^{-1}, 0.1 \%$ strain) at the peptide concentration of $50 \mathrm{mg} \mathrm{mL}^{-1}$ while the concentration of acrylamide was always $25 \mathrm{mg} \mathrm{mL}^{-1}$. The molar ratios of peptides and $\mathrm{ZnCl}_{2}$ in GGH and GHHPH hydrogels were $15: 3$ and 15:9, respectively. (F) $\mathrm{G}^{\prime}$ and $G^{\prime \prime}$ of the hydrogels measured in a strain sweep experiment (strains from 0.01 to $100 \%$, a frequency of $6.28 \mathrm{rad} \mathrm{s}^{-1}$ ) at the peptide concentration of $50 \mathrm{mg} \mathrm{mL}^{-1}$, while the concentration of acrylamide was always $25 \mathrm{mg} \mathrm{mL}^{-1}$ and molar ratio of peptides and $\mathrm{ZnCl}_{2}$ were 15:3 and 15:9 for GGH and GHHPH hydrogels, respectively. (G) $\mathrm{G}^{\prime}$ and $\mathrm{G}^{\prime \prime}$ of the hydrogels measured in a destroy-recovery experiment at the peptide concentration of $50 \mathrm{mg} \mathrm{mL}^{-1}$ while the concentration of acrylamide was always $25 \mathrm{mg} \mathrm{mL}^{-1}$ and molar ratios of peptides and $\mathrm{ZnCl}_{2}$ were 15:3 and 15:9 for GGH and GHHPH hydrogels, respectively. The strain was set to an amplitude of $1000 \%$ for $60 \mathrm{~s}$ to destroy the coordination interactions and switched back to an amplitude of $0.1 \%$ to monitor the recovery of the mechanical properties for $600 \mathrm{~s}$. The $\mathrm{G}^{\prime}$ and $\mathrm{G}^{\prime \prime}$ were measured at a frequency of $6.28 \mathrm{rad} \mathrm{s}^{-1}$ at $20^{\circ} \mathrm{C}$.

\subsubsection{Dynamic Mechanical Properties of the Self-Healing Hydrogels}

The dynamic mechanical properties of the two kinds of hydrogels were investigated using dynamic shear rheology. As shown in Figure 1E, the $\mathrm{G}^{\prime}$ (storage modulus) of all hydrogels was obviously larger than $G^{\prime \prime}$ (loss modulus), indicating solid rather than viscous response of the gel. The $G^{\prime}$ increased with the increase of peptide concentrations (Figure S3). The $\mathrm{G}^{\prime}$ and $\mathrm{G}^{\prime \prime}$ of GHH hydrogels crossed at a frequency of $\sim 100 \mathrm{rad} \mathrm{s}^{-1}$. This suggested that the histidine- $\mathrm{Zn}^{2+}$ coordination bonds in both hydrogels were highly dynamic with a characteristic lifetime shorter than $0.03 \mathrm{~s}$. In comparison, GHHPH hydrogels were stiffer than GGH hydrogels at the same peptide concentrations, as evidenced 
by their higher storage modulus $\mathrm{G}^{\prime}$ (Figure 1E and Figure S3). No crossover of $\mathrm{G}^{\prime}$ and $\mathrm{G}^{\prime \prime}$ was observed, suggesting that the binding of GHHPH became much static. Moreover, the strain sweep experiments were also performed (Figure 1F). The yield strength values of GGH and GHHGH hydrogels were $354 \mathrm{~Pa}$ and $432 \mathrm{~Pa}$, respectively, indicating that both the gels can undergo plastic deformation at low amplitudes (Figure 1F). Furthermore, all hydrogels, except for GGH hydrogel at the low peptide concentration of $25 \mathrm{mg} \mathrm{mL}^{-1}$, can survive up to $100 \%$ strain, suggesting that the hydrogels were mechanically quite robust (Figure S4). For comparison, the covalent hydrogels cross-linked by bis-acrylamide with the same cross-linking density was studied as the control group (Figure S5A). The G' and G" of the hydrogel with covalent network were similar with those of GGH and GHHGH hydrogels.

Then the reassociation of the peptide- $\mathrm{Zn}^{2+}$ bonds was studied after a large strain oscillatory breakdown at $20^{\circ} \mathrm{C}$ (Figure $1 \mathrm{G}$ and Figure S6). Both GGH and GHHPH hydrogels can be fractured at strains higher than $1000 \%$ due to the mechanical rupture of the peptide- $\mathrm{Zn}^{2+}$ cross-linkers. However, both the $G^{\prime}$ and $G^{\prime \prime}$ can be fully recovered in a few seconds, suggesting that these hydrogels may own self-healing properties owing to the fast reassociation of the coordination bonds. The recovery of GHHPH hydrogels was even faster, suggesting that the histidine residues in the peptide may exhibit certain cooperativity for $\mathrm{Zn}^{2+}$ binding.

\subsubsection{Tensile Mechanical Properties of the Self-Healing Hydrogels}

Next, the tensile mechanical properties of the hydrogels were measured by standard tensile tests. The typical tensile stress-strain curves with different mass ratios of the acryloyl-terminated peptide and acrylamide (w/w 1:1, 2:1 and 3:1) are shown in Figure 2A,C and the degree of polymerization, solid content, and mechanical properties were summarized in Table 1. Similar to the rheological properties, the tensile mechanical properties, including fracture stress, Young's modulus, and toughness of GHHPH hydrogels were systematically higher than that of GGH hydrogels. The maximum toughness of GGH hydrogels was $868.07 \mathrm{~kJ} \mathrm{~m}^{-3}$ while that of GHHPH hydrogels reached more than $1300 \mathrm{~kJ} \mathrm{~m}^{-3}$. Increasing peptide concentrations led to higher stiffness and toughness of the hydrogels, suggesting that the mechanical properties can be manipulated by adjusting the density of the cross-linkers. It is worth mentioning that the solid contents of these hydrogels were different and in a range of $22.79 \%$ to $31.69 \%$ (Table 1). However, due to the different $\mathrm{Zn}^{2+}$ binding ability and swelling ratios of these hydrogels, the solid content was difficult to predict a priori. Nonetheless, the dramatic difference in Young's moduli and strain limit for all these hydrogels cannot be attributed to the variation of the solid contents. The different coordination numbers of the cross-linkers played the major role. In comparison, the stretchability and toughness of the covalent hydrogels were much lower than that of GGH and GHHGH hydrogels (Figure S5B).

Furthermore, the mechanical properties of the hydrogels with different tensile strain rates were also studied in order to determine the reversibility of the cross-linkers. As shown in Figure 2B,D, the fracture strain of both kinds of hydrogels became larger as the tensile strain rate decreased, indicating that the toughness of the hydrogels increased as the strain rate increased. However, the Young's modulus of the hydrogels almost remained unchanged with the increase of strain rates, suggesting that the change of strain rates would not affect the elasticity of the hydrogels. The independent control of the toughness and elasticity demonstrated that the cross-links based on the coordination between the designed peptides and $\mathrm{Zn}^{2+}$ ions were reversible, which is consistent with recent experimental studies [61,62] and theoretic work [63]. According to the theory [63], to have the strain rate independent elasticity, the strain rate timescale should be longer than the timescale of reversible dissociation/association of the cross-linkers. Therefore, the coordination bonds between GGH/GHHPH and $\mathrm{Zn}^{2+}$ have reversible dynamics at a timescale shorter than $2 \mathrm{~s}$. Due to the limited strain rate available in our tensile test machine, which cannot go beyond $3000 \% \mathrm{~min}^{-1}$ in the experiments, the exact reversible dynamics cannot be obtained. Nonetheless, it is clear that GHHPH can still retain high dissociation/association rates with $\mathrm{Zn}^{2+}$ in the cross-linking site, which is the prerequisite for fast self-healing. 
Table 1. Degree of polymerization, solid content, and mechanical properties of GGH and GHHPH hydrogels of different peptide concentrations.

\begin{tabular}{|c|c|c|c|c|c|c|c|}
\hline \multicolumn{2}{|c|}{$\begin{array}{l}\text { Mass Concentration of } \\
\text { Peptide }\left(\mathrm{mg} \mathrm{mL}^{-1}\right)\end{array}$} & $\begin{array}{c}\begin{array}{c}\text { Polymerization } \\
\text { Degree }(\%)\end{array} \\
32.8\left(\mathrm{M}_{\mathrm{n}}=21,156\right) \\
\end{array}$ & $\begin{array}{c}\begin{array}{c}\text { Solid Content } \\
(\%)\end{array} \\
25.84 \pm 2.29 \\
\end{array}$ & $\begin{array}{c}\begin{array}{c}\text { Tension Strain } \\
\text { Limit (\%) }\end{array} \\
899.8 \pm 56.1 \\
\end{array}$ & $\begin{array}{c}\begin{array}{c}\text { Tension Stress } \\
\text { Limit }(\mathbf{k P a})\end{array} \\
18.6 \pm 1.61 \\
\end{array}$ & $\begin{array}{c}\begin{array}{c}\text { Young's Modulus } \\
\text { (kPa) }\end{array} \\
1.1 \pm 2.9 \\
\end{array}$ & 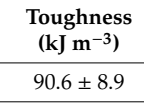 \\
\hline \multirow[t]{2}{*}{ GGH } & 50 & $36.2\left(\mathrm{M}_{\mathrm{n}}=17,521\right)$ & $31.69 \pm 2.56$ & $793.5 \pm 63.4$ & $282.9 \pm 37.6$ & $6.1 \pm 3.6$ & $868.1 \pm 23.3$ \\
\hline & 75 & $42.7\left(\mathrm{M}_{\mathrm{n}}=18,318\right)$ & $31.39 \pm 2.13$ & $687.5 \pm 54.9$ & $220.3 \pm 22.1$ & $18.2 \pm 4.2$ & $586.7 \pm 15.1$ \\
\hline \multirow[b]{2}{*}{ GHHPH } & 25 & $23.9\left(\mathrm{M}_{\mathrm{n}}=28,522\right)$ & $22.79 \pm 2.05$ & $781.0 \pm 70.5$ & $208.8 \pm 23.7$ & $7.1 \pm 3.5$ & $630.6 \pm 50.4$ \\
\hline & 50 & $31.2\left(\mathrm{M}_{\mathrm{n}}=27,930\right)$ & $26.67 \pm 1.89$ & $619.1 \pm 49.5$ & $561.2 \pm 44.9$ & $14.9 \pm 7.1$ & $1348.4 \pm 107.8$ \\
\hline
\end{tabular}

A

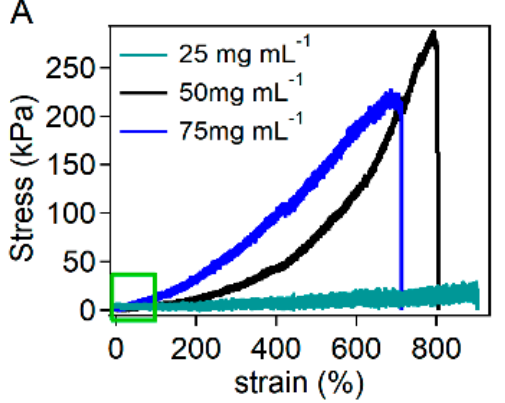

C

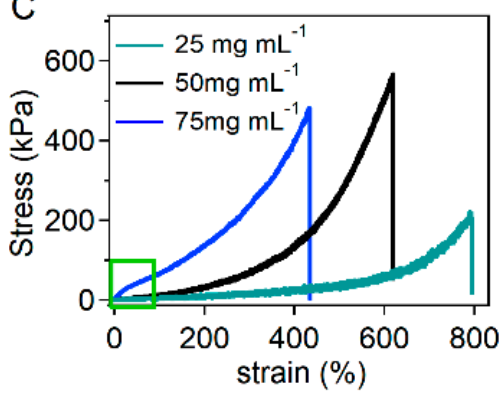

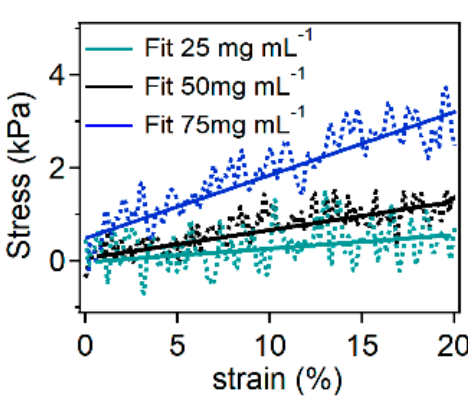
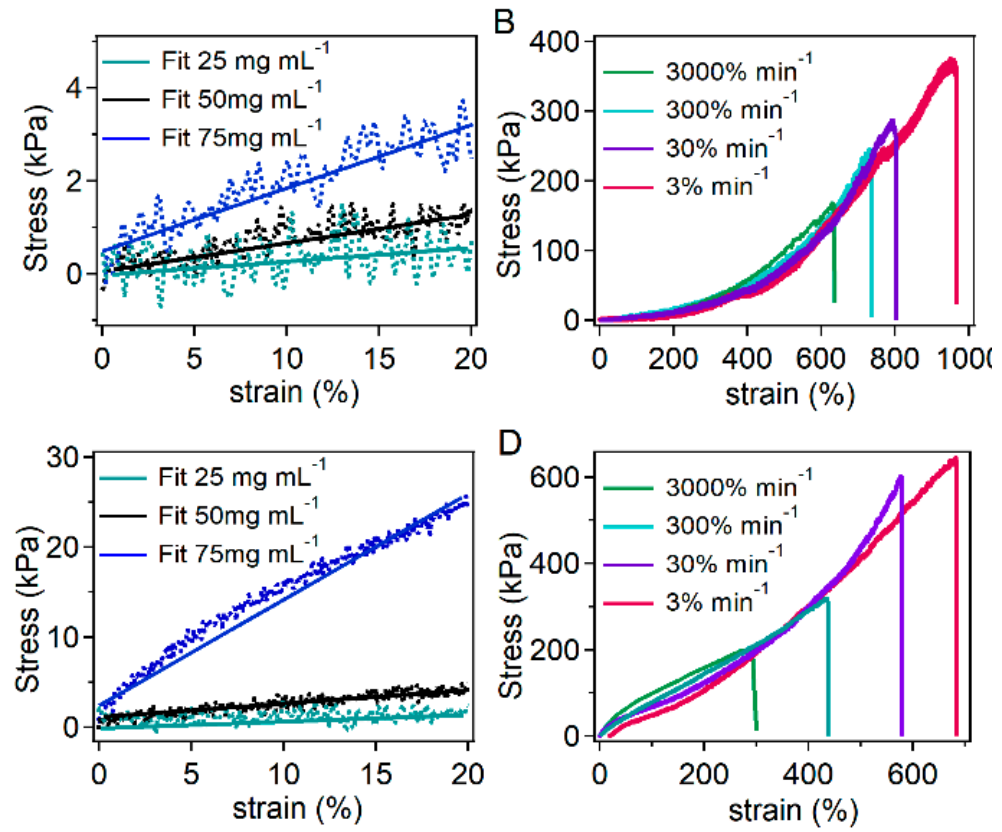

Figure 2. Tensile mechanical properties of GGH and GHHPH hydrogels. (A) Stress-strain curves (left) of GGH hydrogels and zoomed stress-strain curves (right) at the strain rate of $30 \% \mathrm{~min}^{-1}$ with different mass ratios of GGH and acrylamide (1:1, 2:1, and 3:1). The solid lines in the right indicate the linear fitting of the elastic region. The concentrations of GGH peptides were $25 \mathrm{mg} \mathrm{mL}^{-1}, 50 \mathrm{mg} \mathrm{mL}^{-1}$, and $75 \mathrm{mg} \mathrm{mL}^{-1}$, respectively, while the concentration of acrylamide was always $25 \mathrm{mg} \mathrm{mL}^{-1}$ and the molar ratios of peptides and $\mathrm{ZnCl}_{2}$ were always 15:3. (B) Stress-strain curves of GGH hydrogels $\left(m_{\mathrm{GGH}}: m_{\text {acrylamide }}=2: 1\right)$ with different tensile strain rates $(3 \%, 30 \%, 300 \%$ and $3000 \%$ per minute). (C) Stress-strain curves (left) of GHHPH hydrogels and zoomed stress-strain curves (right) at the strain rate of $30 \% \mathrm{~min}^{-1}$ with different mass ratios of GHH and acrylamide (1:1, 2:1, and 3:1). The solid lines in the right indicate the linear fitting of the elastic region. The concentrations of GHHPH peptides were $25 \mathrm{mg} \mathrm{mL}^{-1}, 50 \mathrm{mg} \mathrm{mL}^{-1}$, and $75 \mathrm{mg} \mathrm{mL}^{-1}$, respectively, while the concentration of acrylamide was always $25 \mathrm{mg} \mathrm{mL}^{-1}$ and the molar ratios of peptides and $\mathrm{ZnCl}_{2}$ were always 15:9. (D) Stress-strain curves of GHHPH hydrogels $\left(m_{\mathrm{GHHPH}}: m_{\text {acrylamide }}=2: 1\right)$ with different tensile strain rates $(3 \%, 30 \%$, $300 \%$ and $3000 \% \mathrm{~min}^{-1}$ ).

At last, the tensile experiments with multiple cyclic loading were also performed to investigate the dissipated energy, fatigue, and plastic deformation (Figure S7). The energy dissipation of GGH and GHHGH hydrogels reached $172.4 \mathrm{~kJ} \mathrm{~m}^{-3}$ and $413.0 \mathrm{~kJ} \mathrm{~m}^{-3}$, respectively, in the first tensile cycle, exhibiting excellent energy dissipation properties due to the absence of covalent cross-linkers. The dissipated energy and maximum stress changes are also summarized in Figure S7C,D. The dissipated energy as well as the maximum stress decreased significantly after multiple cyclic loading. However, the dissipated energy remained more than $20 \%$ after seven tensile cycles, indicating that the peptide- $\mathrm{Zn}^{2+}$ coordination bonds can partially reform during relaxation. The decrease of 
dissipated energy and maximum stress suggested the fast accumulation of plastic deformation and fatigue of the hydrogels.

\subsubsection{Self-Healing Properties of the Hydrogels}

Next, we tested the self-healing properties of the hydrogels. In a typical self-healing experiment, the hydrogel was cut into two pieces and put together to self-heal for different times under slight pressure provided by two parallel disk plates in Tris buffer $(\mathrm{pH}=7.60$, containing $100 \mathrm{mM}$ Tris and $300 \mathrm{mM} \mathrm{KCl}$ ). The representative images of hydrogels before and after healing, stress-strain curves and normalized recovery percentage of the mechanical properties are illustrated in Figure 3. Obviously, longer healing time led to higher recovery percentages. For GGH hydrogels, the fracture strain can reach the initial level after healing for $60 \mathrm{~min}$ and the fracture stress and toughness can reach $\sim 80 \%$ of the initial level. For GHHPH hydrogels, the fracture strain can be fully recovered after healing for $60 \mathrm{~min}$ and the fracture stress and toughness can reach about $90 \%$ of the initial level. The self-healing of the GHHPH hydrogels was slightly higher than that of GGH hydrogels, probably due to higher cooperativity of the bonds between GHHPH and $\mathrm{Zn}^{2+}$ ions than that of GGH and $\mathrm{Zn}^{2+}$. These experiments confirmed that the hydrogels based on the coordination bonds between GHHPH and $\mathrm{Zn}^{2+}$ ions showed combined high stretchability, great mechanical strength and fast self-healing properties. In comparison, no self-healing property was observed in the covalent hydrogels (Figure S5C).
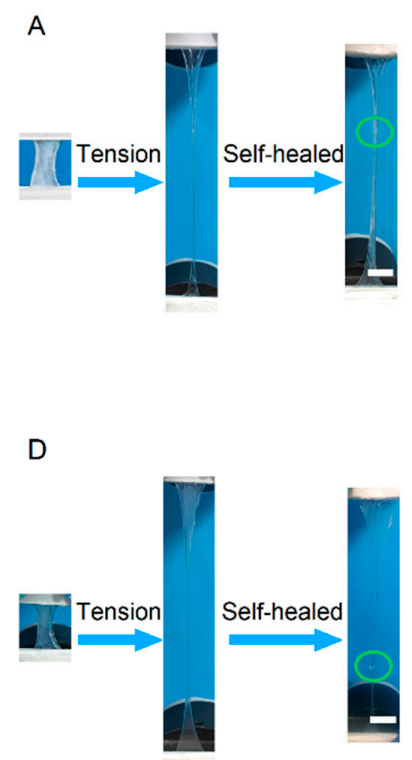

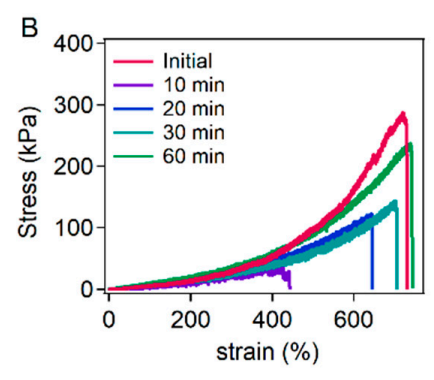

E

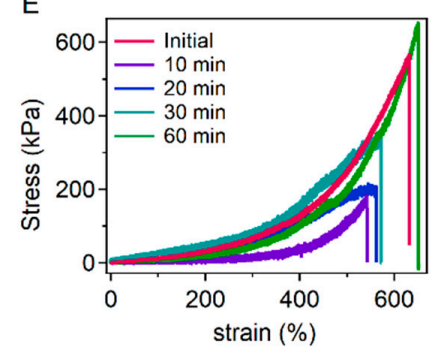

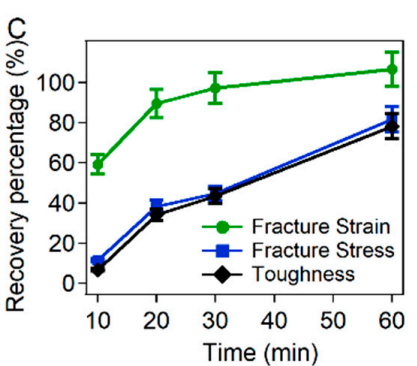

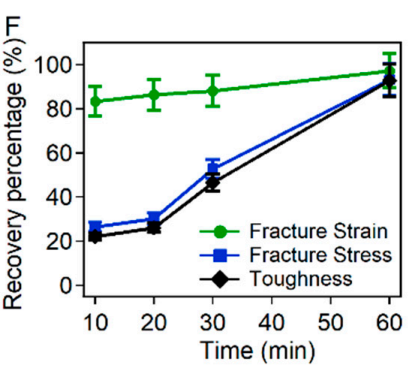

Figure 3. Self-healing properties of GGH and GHHPH hydrogels. (A) Stretching photograph of the GGH hydrogel before and after healing. The reconnected points are highlighted with a green cycle. Scale bar $=5 \mathrm{~mm}$. (B) Stress-strain curves of GGH hydrogels at the strain rate of $30 \% \mathrm{~min}^{-1}$ healed for different times at room temperature. The concentrations of GGH peptides and acrylamide were $50 \mathrm{mg} \mathrm{mL}^{-1}$ and $25 \mathrm{mg} \mathrm{mL}^{-1}$, respectively, while the molar ratios of peptides and $\mathrm{ZnCl}_{2}$ were always 15:3. (C) Normalized recovery percentages of fracture strain, fracture stress and toughness with different healing time corresponding to (B). (D) Stretching photograph of the GHHPH hydrogel before and after healing. The reconnected points are highlighted with a green cycle. Scale bar $=5 \mathrm{~mm}$. (E) Stress-strain curves of GHHPH hydrogels at the strain rate of $30 \% \mathrm{~min}^{-1}$ healed for different times at room temperature. The concentrations of $\mathrm{GHHPH}$ peptides and acrylamide were $50 \mathrm{mg}$ $\mathrm{mL}^{-1}$ and $25 \mathrm{mg} \mathrm{mL}^{-1}$, respectively, while the molar ratios of peptides and $\mathrm{ZnCl}_{2}$ were always 15:9. (F) Normalized recovery percentages of fracture strain, fracture stress and toughness with different healing time corresponding to (E). 
Furthermore, the self-healing of hydrogels with different molar ratios of peptides and $\mathrm{Zn}^{2+}$ ions was also investigated in order to study the effects of $\mathrm{Zn}^{2+}$ ion concentrations on the self-healing properties (Figure 4). For GGH hydrogels, the molar ratios of peptides and $\mathrm{Zn}^{2+}$ ions were set as 15:1, 15:3 and 15:4, respectively. As shown in Figure 4C, the self-healing percentage of the fracture strain, fracture stress and toughness increased with the increasing molar ratios of $\mathrm{Zn}^{2+}$ ions and peptides, indicating that the self-healing ability was enhanced as the $\mathrm{Zn}^{2+}$ concentration increased. For GHHPH hydrogels, the molar ratios of peptide and $\mathrm{Zn}^{2+}$ ions were set as 15:3, 15:9, and 15:12 to ensure the ratios of histidine and $\mathrm{Zn}^{2+}$ ions were the same as those in GGH hydrogels (Figure 4B). Similarly, the self-healing percentages increased with the increase of $\mathrm{Zn}^{2+}$ concentrations (Figure 4D). All these results showed that the self-healing properties of the hydrogels can be further improved by the presence of additional metal ions, which increased the apparent association rates of peptides and $\mathrm{Zn}^{2+}$ ions.
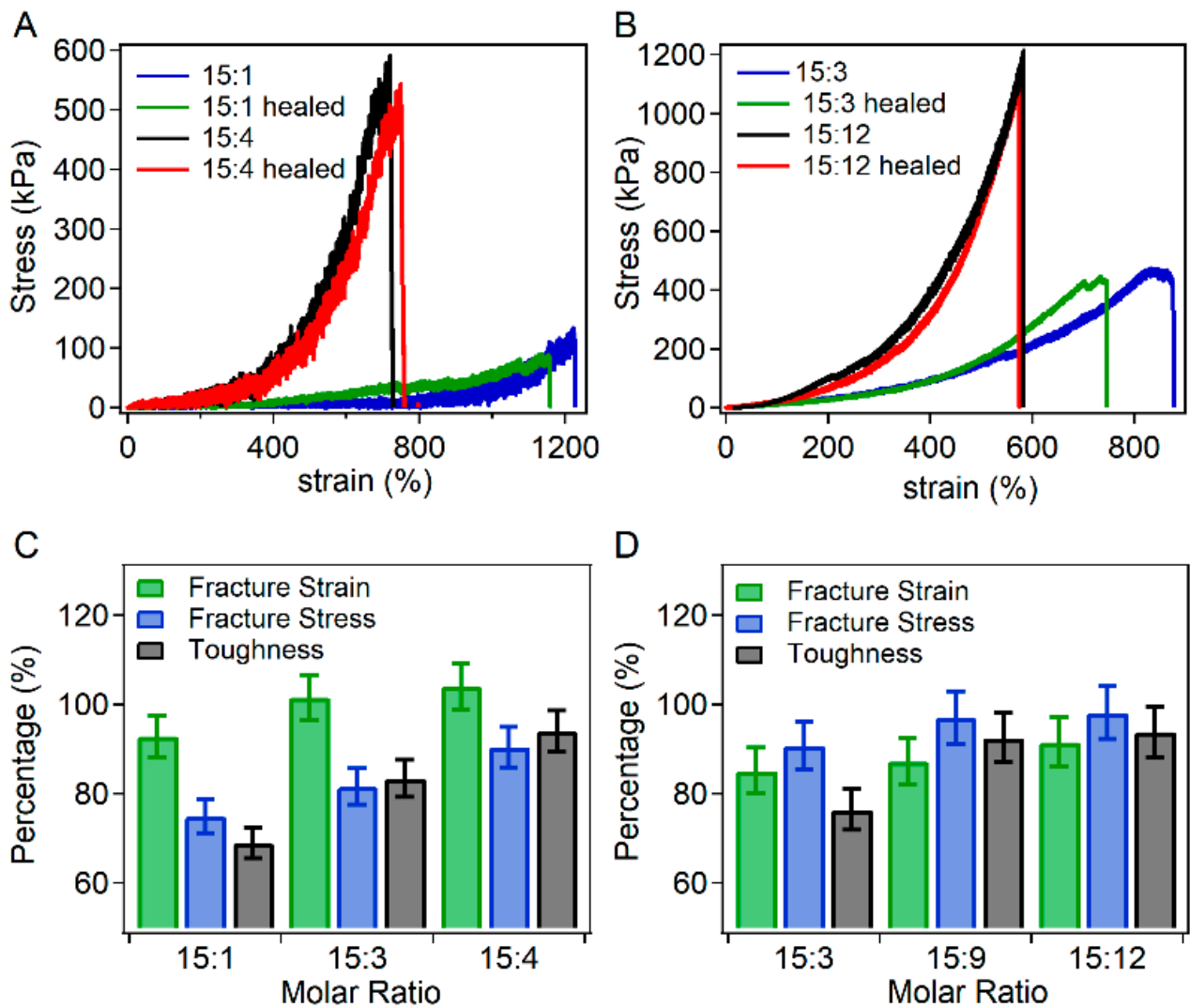

Figure 4. Self-healing properties of GGH and GHHPH hydrogels with different molar ratios of peptide and $\mathrm{Zn}^{2+}$ ions. (A) Stress-strain curves of GGH hydrogels at the strain rate of $30 \% \mathrm{~min}^{-1}$ before and after healing with different molar ratios of peptide and $\mathrm{Zn}^{2+}$ ions (15:1 and 15:4). The concentrations of GGH peptides and acrylamide were $50 \mathrm{mg} \mathrm{mL}^{-1}$ and $25 \mathrm{mg} \mathrm{mL}^{-1}$ respectively. (B) Stress-strain curves of GHHPH hydrogels at the strain rate of $30 \% \mathrm{~min}^{-1}$ before and after healing with different molar ratios of peptide and $\mathrm{Zn}^{2+}$ ions $(15: 3,15: 12)$. The concentrations of GGH peptides and acrylamide were $50 \mathrm{mg} \mathrm{mL}^{-1}$ and $25 \mathrm{mg} \mathrm{mL}^{-1}$, respectively. (C) Normalized recovery percentages of fracture strain, fracture stress and toughness with different ratios of GGH and $\mathrm{Zn}^{2+}$ ions. (D) Normalized recovery percentages of fracture strain, fracture stress and toughness with different ratios of GHHPH and $\mathrm{Zn}^{2+}$ ions.

\section{Discussion}

Although metal coordination bonds have been extensively used as reversible dynamic bonds for engineering self-healing hydrogels, a major challenge is that the resulting hydrogels have limited mechanical strength. However, the mechanical properties are essential for many biological applications, 
such as wound dressing and soft tissue medical adhesive, because the hydrogels are subjected to substantial mechanical stress in these applications. In this work, we showed that the toughness of the hydrogels can be greatly improved by using peptide cross-linkers of high coordination number (the number of binding sites in each cross-linking ligand). Due to the formation of multiple metal coordination bonds in each cross-linking ligand, the mechanical load can be evenly distributed to the bonds thus allowing them to bear larger overall mechanical forces. Therefore, the toughness of the hydrogels is significantly increased comparing to the single-bond cross-linkers. Moreover, due to the formation of specific metal ion binding sites, the association rates of peptides to metal ions are also faster than that of individual ligands. This leads to faster self-healing. Therefore, by simply tuning the coordination number (the number of binding sites in each cross-linking ligand), we were able to obtain hydrogels with combined high stretchability, toughness, and fast recovery. Note that this approach is distinct from the way of tuning the metal-ligand dynamics. It is worth noting that in our system, the maximum coordination number of $\mathrm{Zn}^{2+}$ ions is four. In order to form intermolecular cross-linking, the number of histidine residues in each peptide cannot be higher than four, which prevented us from testing hydrogels cross-linked ligands with other coordination numbers. To further validate this conclusion, future work using synthetic ligands and metal ions with higher coordination numbers is required.

Although it is possible to increase the toughness of hydrogels by making the metal coordination bonds less dynamic, the self-healing properties are compromised because the reassociation of the metal coordination bonds is retarded. Therefore, our approach provides a novel and efficient means for the construction of tough yet self-healable hydrogels. We envision that there is much room to tune the mechanical properties of the self-healing hydrogels by optimizing the cooperativity of dynamical interactions at the molecular level. For example, using nanoparticle cross-linkers or multivalent protein domains as the cross-linkers may further boost the mechanical features of self-healing hydrogels, which are certainly our next endeavors.

\section{Conclusions}

In summary, we have engineered highly stretchable, tough and self-healing hydrogels based on the coordination of peptides and metal ions. We showed that by increasing the coordination number of the binding sites (the number of binding sites in each cross-linking ligand), the toughness of the hydrogels can be greatly improved without sacrificing the stretchability and self-healing of the hydrogels. The resulting hydrogels can achieve a rigorous set mechanical characteristic, including the Young's modulus of $15 \mathrm{kPa}$, the fracture strain of $620 \%$, the toughness of $1350 \mathrm{~kJ} \mathrm{~m}^{-3}$, and the self-healing time of $\sim 1 \mathrm{~h}$. These properties may allow the hydrogels to be used as artificial skins or bioactive coatings for wound dressing. Moreover, the mechanical and self-healing properties can be tuned by adjusting the concentrations of the peptides and metal ions to match the mechanical properties of other biological tissues and to explore other biomedical applications. The concept of using higher number of binding sites in each cross-linking ligand to enhance the mechanical strength of self-healing hydrogels may open doors to design and engineer mechanically tough, highly stretchable and fast self-healing hydrogels.

Supplementary Materials: The Supplementary Materials are available online at http://www.mdpi.com/23137673/4/2/36/s1: Figure S1. Dynamic mechanical properties of GGH and GHHPH Pre-gels without $\mathrm{Zn}^{2+}$ ion; Figure S2. SEM images of lyophilized GGH and GHHPH hydrogels; Figure S3. Rheological mechanical properties of GGH and GHHPH hydrogels in frequency sweep experiments; Figure S4. Rheological mechanical properties of GGH and GHHPH hydrogels in strain sweep experiments; Figure S5. Rheological mechanical properties in frequency sweep experiments, tensile experiments and self-healing properties of the covalent hydrogels; Figure S6. Rheological mechanical properties of GGH and GHHPH hydrogels in destroy-recovery experiments; Figure S7. Tensile experiments with multiple cyclic loading; Table S1. Details of all parameters and formulations in the article.

Author Contributions: Conceptualization, Y.C. and Y.L.; Methodology, L.Z. and M.S.; Software, B.X.; Validation, L.Z. and M.S.; Formal Analysis, B.X. and M.S.; Investigation, L.Z., M.S., and Z.X.; Resources, Y.C.; Data Curation, L.Z. and M.S.; Writing-Original Draft Preparation, B.X.; Writing-Review and Editing, Y.C. and Y.L.; Visualization, L.Z.; Supervision, Y.C., Y.L., and B.X.; Project Administration, Y.C.; Funding Acquisition, Y.C., Y.L., and B.X. 
Funding: This work is supported by the National Natural Science Foundation of China (Grant No. 11674153, 11804148, and 11804147), the Priority Academic Program Development (PAPD) of Jiangsu Higher Education Institutions, the Natural Science Foundation of Jiangsu Province (No. BK20180320), and the Fundamental Research Funds for the Central Universities.

Conflicts of Interest: The authors declare no conflict of interest.

\section{References}

1. Li, Q.; Liu, C.; Wen, J.; Wu, Y.; Shan, Y.; Liao, J. The design, mechanism and biomedical application of self-healing hydrogels. Chin. Chem. Lett. 2017, 28, 1857-1874. [CrossRef]

2. Taylor, D.L.; in het Panhuis, M. Self-healing hydrogels. Adv. Mater. 2016, 28, 9060-9093. [CrossRef] [PubMed]

3. Timin, A.S.; Gould, D.J.; Sukhorukov, G.B. Multi-layer microcapsules: Fresh insights and new applications. Expert Opin. Drug Deliv. 2017, 14, 583-587. [CrossRef] [PubMed]

4. Liu, Y.; Hsu, S.-H. Synthesis and biomedical applications of self-healing hydrogels. Front. Chem. 2018, 6, 449. [CrossRef]

5. Shi, L.; Ding, P.; Wang, Y.; Zhang, Y.; Ossipov, D.; Hilborn, J. Self-healing polymeric hydrogel formed by metal-ligand coordination assembly: Design, fabrication, and biomedical applications. Macromol. Rapid Commun. 2019, 40, 1800837. [CrossRef] [PubMed]

6. Saunders, L.; Ma, P.X. Self-healing supramolecular hydrogels for tissue engineering applications. Macromol. Biosci. 2019, 19, 1800313. [CrossRef]

7. Wang, Y.; Park, J.P.; Hong, S.H.; Lee, H. Biologically inspired materials exhibiting repeatable regeneration with self-sealing capabilities without external stimuli or catalysts. Adv. Mater. 2016, 28,9961-9968. [CrossRef]

8. Hong, S.; Schaber, C.F.; Dening, K.; Appel, E.; Gorb, S.N.; Lee, H. Air/water interfacial formation of freestanding, stimuli-responsive, self-healing catecholamine janus-faced microfilms. Adv. Mater. 2014, 26, 7581-7587. [CrossRef]

9. Guan, Y.; Zhang, Y. Boronic acid-containing hydrogels: Synthesis and their applications. Chem. Soc. Rev. 2013, 42, 8106-8121. [CrossRef]

10. Sun, W.; Jiang, H.; Wu, X.; Xu, Z.; Yao, C.; Wang, J.; Qin, M.; Jiang, Q.; Wang, W.; Shi, D.; et al. Strong dual-cross-linked hydrogels for ultrasound-triggered drug delivery. Nano Res. 2019, 12, 115-119. [CrossRef]

11. He, L.; Fullenkamp, D.E.; Rivera, J.G.; Messersmith, P.B. pH responsive self-healing hydrogels formed by boronate-catechol complexation. Chem. Commun. 2011, 47, 7497-7499. [CrossRef]

12. Deng, C.C.; Brooks, W.L.A.; Abboud, K.A.; Sumerlin, B.S. Boronic acid-based hydrogels undergo self-healing at neutral and acidic pH. ACS Macro Lett. 2015, 4, 220-224. [CrossRef]

13. Cromwell, O.R.; Chung, J.; Guan, Z. Malleable and self-healing covalent polymer networks through tunable dynamic boronic ester bonds. J. Am. Chem. Soc. 2015, 137, 6492-6495. [CrossRef]

14. Huang, Z.; Delparastan, P.; Burch, P.; Cheng, J.; Cao, Y.; Messersmith, P.B. Injectable dynamic covalent hydrogels of boronic acid polymers cross-linked by bioactive plant-derived polyphenols. Biomater. Sci. 2018, 6, 2487-2495. [CrossRef]

15. Zhang, Y.; Tao, L.; Li, S.; Wei, Y. Synthesis of multiresponsive and dynamic chitosan-based hydrogels for controlled release of bioactive molecules. Biomacromolecules 2011, 12, 2894-2901. [CrossRef]

16. Lü, S.; Gao, C.; Xu, X.; Bai, X.; Duan, H.; Gao, N.; Feng, C.; Xiong, Y.; Liu, M. Injectable and self-healing carbohydrate-based hydrogel for cell encapsulation. ACS Appl. Mater. Interfaces 2015, 7, 13029-13037. [CrossRef] [PubMed]

17. Chang, R.; Wang, X.; Li, X.; An, H.; Qin, J. Self-activated healable hydrogels with reversible temperature responsiveness. ACS Appl. Mater. Interfaces 2016, 8, 25544-25551. [CrossRef] [PubMed]

18. Wei, Z.; Yang, J.H.; Liu, Z.Q.; Xu, F.; Zhou, J.X.; Zrínyi, M.; Osada, Y.; Chen, Y.M. Novel biocompatible polysaccharide-based self-healing hydrogel. Adv. Funct. Mater. 2015, 25, 1352-1359. [CrossRef]

19. Mukherjee, S.; Hill, M.R.; Sumerlin, B.S. Self-healing hydrogels containing reversible oxime cross-links. Soft Matter 2015, 11, 6152-6161. [CrossRef] [PubMed]

20. Tuncaboylu, D.C.; Sahin, M.; Argun, A.; Oppermann, W.; Okay, O. Dynamics and large strain behavior of self-healing hydrogels with and without surfactants. Macromolecules 2012, 45, 1991-2000. [CrossRef] 
21. Li, S.; Gao, Y.; Jiang, H.; Duan, L.; Gao, G. Tough, sticky and remoldable hydrophobic association hydrogel regulated by polysaccharide and sodium dodecyl sulfate as emulsifiers. Carbohydr. Polym. 2018, 201, 591-598. [CrossRef] [PubMed]

22. Yeh, M.-Y.; Huang, C.-T.; Lai, T.-S.; Chen, F.-Y.; Chu, N.-T.; Tseng, D.T.-H.; Hung, S.-C.; Lin, H.-C. Effect of peptide sequences on supramolecular interactions of naphthaleneimide/tripeptide conjugates. Langmuir 2016, 32, 7630-7638. [CrossRef]

23. Zhan, J.; Cai, Y.; Ji, S.; He, S.; Cao, Y.; Ding, D.; Wang, L.; Yang, Z. Spatiotemporal control of supramolecular self-assembly and function. ACS Appl. Mater. Interfaces 2017, 9, 10012-10018. [CrossRef]

24. Feng, Z.; Zuo, H.; Gao, W.; Ning, N.; Tian, M.; Zhang, L. A robust, self-healable, and shape memory supramolecular hydrogel by multiple hydrogen bonding interactions. Macromol. Rapid Commun. 2018, 39, 1800138. [CrossRef]

25. Nam, H.G.; Nam, M.G.; Yoo, P.J.; Kim, J.-H. Hydrogen bonding-based strongly adhesive coacervate hydrogels synthesized using poly(n-vinylpyrrolidone) and tannic acid. Soft Matter 2019, 15, 785-791. [CrossRef] [PubMed]

26. Guo, Y.; Zheng, K.; Wan, P. A flexible stretchable hydrogel electrolyte for healable all-in-one configured supercapacitors. Small 2018, 14, 1704497. [CrossRef] [PubMed]

27. Dai, X.; Zhang, Y.; Gao, L.; Bai, T.; Wang, W.; Cui, Y.; Liu, W. A mechanically strong, highly stable, thermoplastic, and self-healable supramolecular polymer hydrogel. Adv. Mater. 2015, 27, 3566-3571. [CrossRef] [PubMed]

28. Wu, D.; Xu, J.; Chen, Y.; Yi, M.; Wang, Q. Gum arabic: A promising candidate for the construction of physical hydrogels exhibiting highly stretchable, self-healing and tensility reinforcing performances. Carbohydr. Polym. 2018, 181, 167-174. [CrossRef]

29. Wu, Q.; Wei, J.; Xu, B.; Liu, X.; Wang, H.; Wang, W.; Wang, Q.; Liu, W. A robust, highly stretchable supramolecular polymer conductive hydrogel with self-healability and thermo-processability. Sci. Rep. 2017, 7, 41566. [CrossRef] [PubMed]

30. Feng, Q.; Wei, K.; Lin, S.; Xu, Z.; Sun, Y.; Shi, P.; Li, G.; Bian, L. Mechanically resilient, injectable, and bioadhesive supramolecular gelatin hydrogels cross-linked by weak host-guest interactions assist cell infiltration and in situ tissue regeneration. Biomaterials 2016, 101, 217-228. [CrossRef]

31. Harada, A.; Takashima, Y.; Nakahata, M. Supramolecular polymeric materials via cyclodextrin-guest interactions. Acc. Chem. Res. 2014, 47, 2128-2140. [CrossRef]

32. Miao, T.; Fenn, S.L.; Charron, P.N.; Oldinski, R.A. Self-healing and thermoresponsive dual-cross-linked alginate hydrogels based on supramolecular inclusion complexes. Biomacromolecules 2015, 16, 3740-3750. [CrossRef]

33. Luo, F.; Sun, T.L.; Nakajima, T.; Kurokawa, T.; Zhao, Y.; Sato, K.; Ihsan, A.B.; Li, X.; Guo, H.; Gong, J.P. Oppositely charged polyelectrolytes form tough, self-healing, and rebuildable hydrogels. Adv. Mater. 2015, 27, 2722-2727. [CrossRef] [PubMed]

34. Grindy, S.C.; Learsch, R.; Mozhdehi, D.; Cheng, J.; Barrett, D.G.; Guan, Z.; Messersmith, P.B.; Holten-Andersen, N. Control of hierarchical polymer mechanics with bioinspired metal-coordination dynamics. Nat. Mater. 2015, 14, 1210. [CrossRef]

35. Liang, H.; Zhang, Z.; Yuan, Q.; Liu, J. Self-healing metal-coordinated hydrogels using nucleotide ligands. Chem. Commun. 2015, 51, 15196-15199. [CrossRef]

36. Holten-Andersen, N.; Jaishankar, A.; Harrington, M.J.; Fullenkamp, D.E.; DiMarco, G.; He, L.; McKinley, G.H.; Messersmith, P.B.; Lee, K.Y.C. Metal-coordination: Using one of nature's tricks to control soft material mechanics. J. Mater. Chem. B 2014, 2, 2467-2472. [CrossRef]

37. Yount, W.C.; Juwarker, H.; Craig, S.L. Orthogonal control of dissociation dynamics relative to thermodynamics in a main-chain reversible polymer. J. Am. Chem. Soc. 2003, 125, 15302-15303. [CrossRef]

38. Kersey, F.R.; Loveless, D.M.; Craig, S.L. A hybrid polymer gel with controlled rates of cross-link rupture and self-repair. J. R. Soc. Interface 2007, 4, 373-380. [CrossRef] [PubMed]

39. Lewis, A.L.; Miller, J.D. Stabilisation of cobalt(I) by coordination within a bipyridyl-based hydrogel polymer membrane. J. Chem. Soc. Chem. Commun. 1992, 14, 1029-1030. [CrossRef]

40. Lewis, A.L.; Miller, J.D. Synthesis, characterisation and complexation behaviour of a series of pyridyl- and bipyridyl-based hydrogel membranes. J. Mater. Chem. 1993, 3, 897-902. [CrossRef] 
41. Chujo, Y.; Sada, K.; Saegusa, T. Iron(II) bipyridyl-branched polyoxazoline complex as a thermally reversible hydrogel. Macromolecules 1993, 26, 6315-6319. [CrossRef]

42. Chujo, Y.; Sada, K.; Saegusa, T. Cobalt(III) bipyridyl-branched polyoxazoline complex as a thermally and redox reversible hydrogel. Macromolecules 1993, 26, 6320-6323. [CrossRef]

43. Barrett, D.G.; Fullenkamp, D.E.; He, L.; Holten-Andersen, N.; Lee, K.Y.C.; Messersmith, P.B. $\mathrm{pH}$-Based regulation of hydrogel mechanical properties through mussel-inspired chemistry and processing. Adv. Funct. Mater. 2013, 23, 1111-1119. [CrossRef] [PubMed]

44. Holten-Andersen, N.; Harrington, M.J.; Birkedal, H.; Lee, B.P.; Messersmith, P.B.; Lee, K.Y.C.; Waite, J.H. $\mathrm{pH}$-induced metal-ligand cross-links inspired by mussel yield self-healing polymer networks with near-covalent elastic moduli. Proc. Natl. Acad. Sci. USA 2011, 108, 2651-2655. [CrossRef] [PubMed]

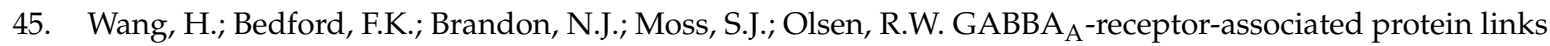
GABBA $_{A}$ receptors and the cytoskeleton. Nature 1999, 397, 69. [CrossRef] [PubMed]

46. Fullenkamp, D.E.; He, L.; Barrett, D.G.; Burghardt, W.R.; Messersmith, P.B. Mussel-inspired histidine-based transient network metal coordination hydrogels. Macromolecules 2013, 46, 1167-1174. [CrossRef]

47. Wu, J.; Li, P.; Dong, C.; Jiang, H.; Bin, X.; Gao, X.; Qin, M.; Wang, W.; Bin, C.; Cao, Y. Rationally designed synthetic protein hydrogels with predictable mechanical properties. Nat. Commun. 2018, 9, 620. [CrossRef]

48. Gao, X.; Fang, J.; Xue, B.; Fu, L.; Li, H. Engineering protein hydrogels using spycatcher-spytag chemistry. Biomacromolecules 2016, 17, 2812-2819. [CrossRef]

49. Li, H.; Kong, N.; Laver, B.; Liu, J. Hydrogels constructed from engineered proteins. Small 2016, 12, $973-987$. [CrossRef]

50. Yount, W.C.; Loveless, D.M.; Craig, S.L. Small-molecule dynamics and mechanisms underlying the macroscopic mechanical properties of coordinatively cross-linked polymer networks. J. Am. Chem. Soc. 2005, 127, 14488-14496. [CrossRef]

51. Yount, W.C.; Loveless, D.M.; Craig, S.L. Strong means slow: Dynamic contributions to the bulk mechanical properties of supramolecular networks. Angew. Chem. Int. Ed. 2005, 44, 2746-2748. [CrossRef]

52. Appel, E.A.; Forster, R.A.; Koutsioubas, A.; Toprakcioglu, C.; Scherman, O.A. Activation energies control the macroscopic properties of physically cross-linked materials. Angew. Chem. 2014, 126, 10202-10207. [CrossRef]

53. Li, Q.; Barrett, D.G.; Messersmith, P.B.; Holten-Andersen, N. Controlling hydrogel mechanics via bio-inspired polymer-nanoparticle bond dynamics. ACS Nano 2016, 10, 1317-1324. [CrossRef]

54. Shabbir, H.; Dellago, C.; Hartmann, M.A. A high coordination of cross-links is beneficial for the strength of cross-linked fibers. Biomimetics 2019, 4, 12. [CrossRef]

55. Filippidi, E.; Cristiani, T.R.; Eisenbach, C.D.; Waite, J.H.; Israelachvili, J.N.; Ahn, B.K.; Valentine, M.T. Toughening elastomers using mussel-inspired iron-catechol complexes. Science 2017, 358, 502-505. [CrossRef]

56. Shin, M.K.; Spinks, G.M.; Shin, S.R.; Kim, S.I.; Kim, S.J. Nanocomposite hydrogel with high toughness for bioactuators. Adv. Mater. 2009, 21, 1712-1715. [CrossRef]

57. Mozhdehi, D.; Ayala, S.; Cromwell, O.R.; Guan, Z. Self-healing multiphase polymers via dynamic metal-ligand interactions. J. Am. Chem. Soc. 2014, 136, 16128-16131. [CrossRef]

58. Schmitt, C.N.; Politi, Y.; Reinecke, A.; Harrington, M.J. Role of sacrificial protein-metal bond exchange in mussel byssal thread self-healing. Biomacromolecules 2015, 16, 2852-2861. [CrossRef]

59. Degtyar, E.; Harrington, M.J.; Politi, Y.; Fratzl, P. The mechanical role of metal ions in biogenic protein-based materials. Angew. Chem. Int. Ed. 2014, 53, 12026-12044. [CrossRef]

60. Morgan, W.T. The histidine-rich glycoprotein of serum has a domain rich in histidine, proline, and glycine that binds heme and metals. Biochemistry 1985, 24, 1496-1501. [CrossRef]

61. Kean, Z.S.; Hawk, J.L.; Lin, S.; Zhao, X.; Sijbesma, R.P.; Craig, S.L. Increasing the maximum achievable strain of a covalent polymer gel through the addition of mechanically invisible cross-links. Adv. Mater. 2014, 26, 6013-6018. [CrossRef] 
62. Mayumi, K.; Guo, J.; Narita, T.; Hui, C.Y.; Creton, C. Fracture of dual cross-link gels with permanent and transient cross-links. Extreme Mech. Lett. 2016, 6, 52-59. [CrossRef]

63. Tito, N.B.; Creton, C.; Storm, C.; Ellenbroek, W.G. Harnessing entropy to enhance toughness in reversibly cross-linked polymer networks. Soft Matter 2019, 15, 2190-2203. [CrossRef] [PubMed] 